\title{
Compressive Strength and Thermal Conductivity of Porous Mullite Ceramics
}

\author{
${ }^{1} \mathrm{M}$. W. Wildan \\ ${ }^{2} \mathrm{~F}$. Marpaung \\ 1,2Department of \\ Mechanical and \\ Industrial Engineering, \\ Faculty of Engineering, \\ Universitas Gadjah \\ Mada. Jl. Grafika 2, \\ Yogyakarta 55281, \\ Indonesia \\ Email:
}

1m wildan@ugm.ac.id

\section{Keywords}

kaolin, mullite, dry yeast powder, porosity, compressive strength, thermal conductivity, PFA (pore-forming agent).

\begin{abstract}
Porous ceramics are a form of ceramic material with widespread applications, such as filters, isolators, and acoustics. This research aimed to investigate the compressive strength and thermal conductivity of porous mullite ceramics (3Al2O3.2SiO2 or Si2Al6O13) produced using dry yeast powder as a PFA (poreforming agent). Kaolin powder (Al2O3.2SiO4.2H2O or $\mathrm{Al} 2 \mathrm{Si} 2 \mathrm{O} 5(\mathrm{OH}) 4)$ was used as a raw material for producing mullite ceramics. Kaolin powder and dry yeast powder were mixed at a variety of dry yeast powder weight fractions: $0 \%, 5 \%, 10 \%, 15 \%$, $20 \%$, and $25 \%$. The composition was mixed using Turbula Mixer for 1 hour. The cylindrical green body (diameters of $12 \mathrm{~mm}, 15$ $\mathrm{mm}$, and $30 \mathrm{~mm}$ ) of every constituent was formed by the uniaxial pressing method at $10 \mathrm{MPa}$. Monolithic kaolin was sintered at variable temperatures $(1,100 \mathrm{oC}, 1,200 \mathrm{oC}, 1,300 \mathrm{oC}, 1,400 \mathrm{oC}$, $1,450 \mathrm{oC})$ for 2 hours then subjected to several tests for its density. From the bulk density tests, it was found that the optimum temperature for 2 -hour sintering was $1,450 \mathrm{oC}$. This temperature was then used for the sintering process of the kaolin specimens which contained dry yeast powder. Testing was performed on the microstructure, bulk density, burning waste in mass and volume, compressive strength, and thermal conductivity. According to the literature, kaolin will transform into mullite $(3 \mathrm{Al} 2 \mathrm{O} 3.2 \mathrm{SiO} 2$ or $\mathrm{Si} 2 \mathrm{Al} 6 \mathrm{O} 13)$ and cristobalite $(\mathrm{SiO} 2)$ at 1,450 oC. It was found that with the increase in the content of dry yeast powder as PFA in the mixture with kaolin, the bulk density decreased (from $2.44 \mathrm{gr} / \mathrm{cm} 3$ to $1.521 \mathrm{gr} / \mathrm{cm} 3$ ), the porosity increased (from $23.77 \%$ to $52.48 \%$ ), the compressive strength decreased (from 38.04 MPa to $4.51 \mathrm{MPa}$ ), and the thermal conductivity decreased (from 3.76 $\mathrm{W} / \mathrm{moC}$ to $1.34 \mathrm{~W} / \mathrm{moC}$ ), each from yeast powder content $0 \%$ to $25 \%$.
\end{abstract}




\section{I}

\section{Introduction}

Engineering ceramics are usually more advantageous than engineering materials of any other types in a variety of aspects, including high strength at high temperaturas, high modulus of elasticity, high hardness, wear resistance, low coefficient of thermal expansión, and relatively low density (Barsoum, 2003). One of the ceramic materials constantly produced is porous ceramic. Porous ceramics have vast applications, for example, in membranes, filters, biomaterials, thermal insulators, and acoustics. As a result, production of porous ceramics with controlled microstructure in terms of porosity, pore size, and pore space topology has become an important, intriguing topic in the last few decades.

Porous ceramics can lower thermal conductivity and at the same time increase thermal resistance, or in other words, they are suited for use as thermal insulators (Barsoum, 2003).

The porous ceramics fabrication methods developing at the present include the sol-gel process (for nanometer-scale pores and high levels of porosity) (Liu and Chen, 2014), the polymer foam-based template method (for big-sized pores and high levels of porosity), the biomimetic method (using pyrolyzed Wood templates), the ceramic hollow spheres method (e.g., alumina microballoons), and the sacrifical (pyrolyzable) pore-forming agent method (PFA) (using organic materials or biopolymers burnable during sintering). Some of the materials which have been developed into forming agents are polymethyl methacrylate (Chen et al., 2005), rice starch and potato starch (Gregorova et al., 2006), poppy seed (Gregorova and Pabst, 2006), rice husk (Manap and Jais, 2009), corn starch (Wildan et al., 2009), and coconut shell charcoal (Sandra et al., 2014). Some formation methods and porous ceramics' properties tests have also been discussed in detail by Hammel et al. (2014).

Mullite ceramics (3Al2O3.2SiO2) are engineering ceramic materials with wide applications, including, for example, refractories, whiteware, and structures. Mullite has a melting point of $1,830 \mathrm{oC}$ in the air, density of $3.16 \mathrm{~g} / \mathrm{cm} 3$, Young's modulus of $50-220 \mathrm{GPa}$, fracture toughness of 2.6 MPa.m0.5, and thermal conductivity of around $6.0 \mathrm{~W} / \mathrm{moC}$ (Kingon and Davis, 2000). Besides, mullite ceramics also have other good properties, namely high temperature stability, relatively low creep rate, low coefficient of thermal expansion, and low thermal conductivity, hence applied for thermal insulation (Chen and Tuan, 2001). The low thermal conductivity can be intensified by making the mullite material porous (Barsoum, 2003). Pores can lower the thermal conductivity of a solid as conductivity in vacuum is lower than in solid matters.

Research in the field of porous ceramics is still open to grow in topics of types of ceramic materials, pore-making methods, measured properties, applications, among others. This research aimed to figure out the compressive strength and thermal conductivity of porous mullite ceramics manufactured using dry yeast powder as a PFA (pore-forming agent). Kaolin powder was used as the raw material to make the mullite ceramics. Ceramic materials have a wide array of applications and relatively low sintering temperatures. The kaolin ceramic material is a refractory material with superiority in physical, mechanical, and thermal properties like being lightweight, hard, resistant to high temperatures, strong, and so forth.

\section{Materials and Methods}

The materials used in this research were kaolin powder (from Sigma Aldrich, serial number: 03584) and active dry yeast 
powder. The particulate size distribution was measured using dry yeast powder by screening. The kaolin powder was mixed with the dry yeast powder at a variety of weight fractions: $0,5,10,10,15,20$, and $25 \%$ dry yeast powder. The composition was mixed together with Turbula Mixer for 1 hour in an alcohol medium. The green body specimens were made by applying uniaxial pressure at 10 $\mathrm{MPa}$. In making the green body specimens, a little bit of molasses was added as a binder to assist in the forming process. Three sizes of cylindrical green body specimens were applied: diameter of $12 \mathrm{~mm}$, thickness of about $10 \mathrm{~mm}$; diameter of $15 \mathrm{~mm}$, thickness of about $5 \mathrm{~mm}$, and diameter of $30 \mathrm{~mm}$, thickness of about $8 \mathrm{~mm}$. The $15-\mathrm{mm}$ diameter cylindrical specimen was subjected to density tests, the 12-mm-diameter cylindrical specimen to compressive strength tests, and the 30-mm-diameter cylindrical specimen to thermal conductivity tests. The 15-mm-diameter cylindrical green body specimen was sintered at variable temperatures $\left(1,100{ }^{\circ} \mathrm{C}, 1,200{ }^{\circ} \mathrm{C}, 1,300{ }^{\circ} \mathrm{C}\right.$, $1,400{ }^{\circ} \mathrm{C}$, and $1,450{ }^{\circ} \mathrm{C}$ ) and heating rate of 7 ${ }^{\circ} \mathrm{C} /$ minute, maintained for 2 hours. The sintering product was then subjected to the density tests by Archimedes's method in a mercury medium. Based on the density data, it was found that sintering at $1,450 \circ \mathrm{C}$ resulted in optimum density. Thus, the temperature $1,450 \circ \mathrm{C}$ was selected as the sintering temperature to be applied to the rest of the specimens. All of the green body specimens were then sintered by pressureless sintering in the air at $1,450{ }^{\circ} \mathrm{C}$ and heating rate of 7 ${ }^{\circ} \mathrm{C} /$ minute, maintained for 2 hours. The bulk density of the sintered specimens was subjected to some tests by Archiedes's method. The compressive strength tests were performed on the $12-\mathrm{mm}$-diameter cylindrical specimen, while the thermal conductivity tests on the 30-mm-diameter cylindrical specimen. The microstructure was observed under a scanning electron microscope (SEM).

\section{Results and Discussion}

The results of the measurement of yeast powder particulate sizes by the screening method is displayed in Figure 1. The varying particulate sizes from $0.297 \mathrm{~mm}$ through 1.68 $\mathrm{mm}$ were distributed (percent weight) as follows: $2 \%$ was sized $1.68 \mathrm{~mm}, 16 \%$ was sized $1.19 \mathrm{~mm}, 23 \%$ was sized $0.841 \mathrm{~mm}, 47 \%$ was sized $0.595 \mathrm{~mm}$, and $11 \%$ was sized 0.297 $\mathrm{mm}$. Figures 2 and 3 display the particulate shapes of the dry yeast powder and the kaolin powder, respectively. The dry yeast powder particles were rounded and nearly spherical, while the kaolin powder particles flat and layered.

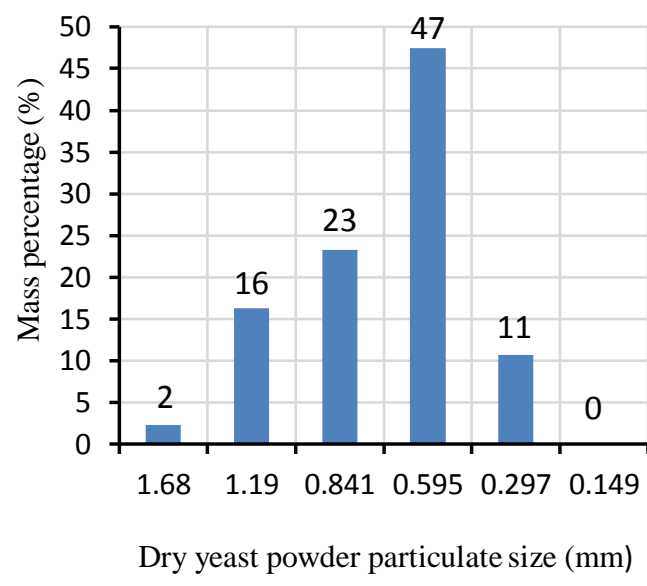

Figure 1. Distribution of dry yeast powder particulate sizes

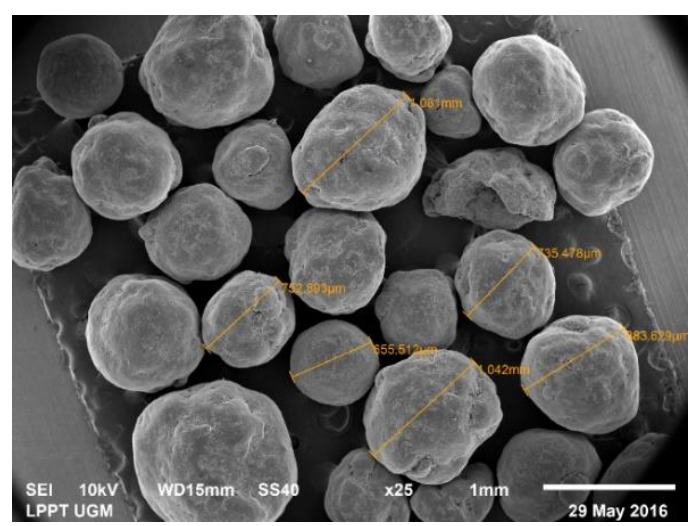

Figure 2. SEM image of dry yeast powder 


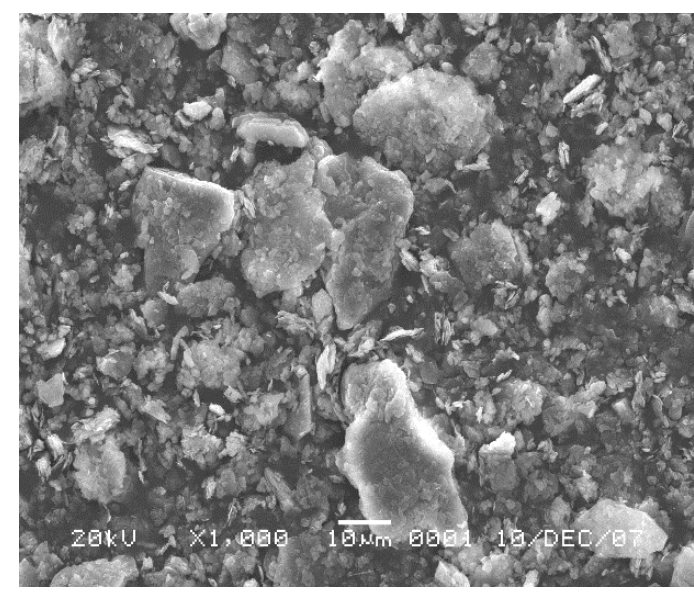

Figure 3. Kaolin powder

The effect of kaolin sintering temperature on the bulk density of the sintering product is shown in Figure 4. As with the sintering process in general, the higher the sintering temperature, the tighter the bond between particles, causing the bulk density and the relative density to also rise. Figure 4 shows that at temperatures between $1,300 \mathrm{oC}$ and $1,450 \mathrm{oC}$, no significant change in density took place. For this reason, 1,450 $\mathrm{oC}$ was selected as the sintering temperature for kaolin.

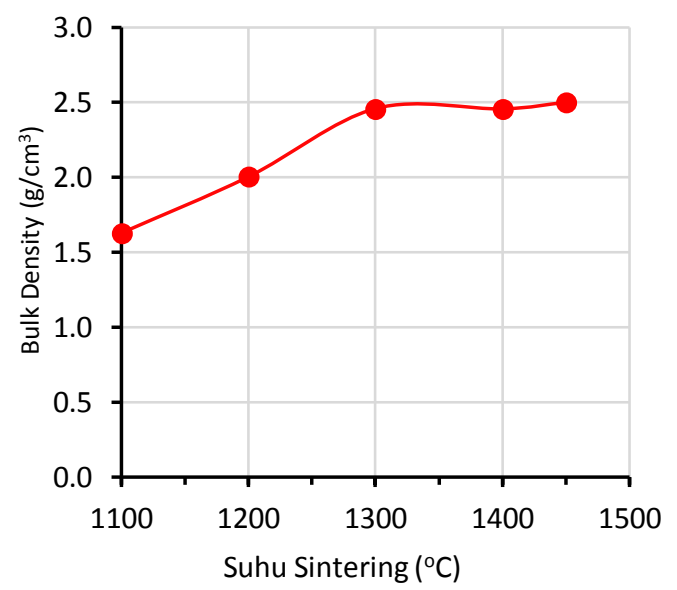

Figure 4. Bulk density of sintered monolithic kaolin as a function of sintering temperature

During a sintering process, kaolin is undergoing a phase transformation into mullite and cristoballite through a number of stages (lee and Reinforth, 1994; Wildan et al., 2009). The transformation stages are as follows:

Kaolin $\left(\mathrm{Al}_{2} \mathrm{O}_{3} \cdot \mathrm{SiO}_{2} .2 \mathrm{H}_{2} \mathrm{O}\right)$ undergoes an endhothermic dehydroxylation reaction starting at 550-600 ${ }^{\circ} \mathrm{C}$ into metakaolin $\left(\mathrm{Al}_{2} \mathrm{Si}_{2} \mathrm{O}_{7}\right)$ until it releases a hydroxyl $(-\mathrm{OH})$ ion at $900{ }^{\circ} \mathrm{C}$.

$2 \mathrm{Al}_{2} \mathrm{Si}_{2} \mathrm{O}_{5}(\mathrm{OH})_{4} \rightarrow 2 \mathrm{Al}_{2} \mathrm{Si}_{2} \mathrm{O}_{7}+4 \mathrm{H}_{2} \mathrm{O}$

The heating carries on, and at 925-950 ${ }^{\circ} \mathrm{C}$ metakaolin transforms into defect aluminumsilicon spinel:

$2 \mathrm{Al}_{2} \mathrm{Si}_{2} \mathrm{O}_{7} \rightarrow \mathrm{Si}_{3} \mathrm{Al}_{4} \mathrm{O}_{12}+\mathrm{SiO}_{2}$

At 1,050 ${ }^{\circ}$, spinel undergoes nucleation and transforms into mullite and cristobalite (high crystalline cristobalite):

$3 \mathrm{Si}_{3} \mathrm{Al}_{4} \mathrm{O}_{12} \rightarrow 2 \mathrm{Si}_{2} \mathrm{Al}_{6} \mathrm{O}_{13}+5 \mathrm{SiO}_{2}$

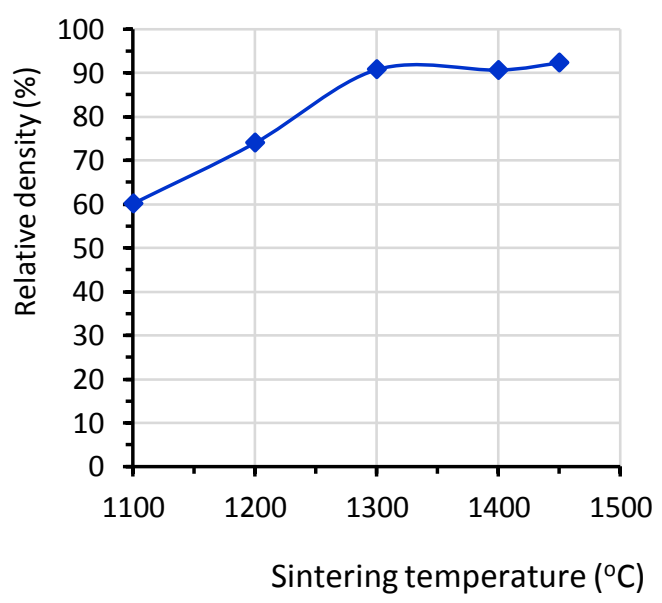

Figure 5. Relative density of sintered monolithic kaolin as a function of sintering temperature

From the sintering process mullite and cristobalite were produced. Based on literature, the theoretical density of mullite is $3.05 \mathrm{~g} / \mathrm{cm} 3$ (mullite data, webmineral.com), 
and cristoballite $2.27 \mathrm{~g} / \mathrm{cm} 3$ (christobalite data, webmineral.com). Following the theoretical density data and the transformation of kaolin into mullite and cristobalite during the sintering precess, the theoretical density of the sintering products was estimated or calculated using the rule of mixture as $2.71 \mathrm{~g} / \mathrm{cm} 3$. Figure 5 shows the relative density of the kaolin sintering products of mullite and cristoballite. The specimens sintered at 1,450 oC generated relative density of over $95 \%$.

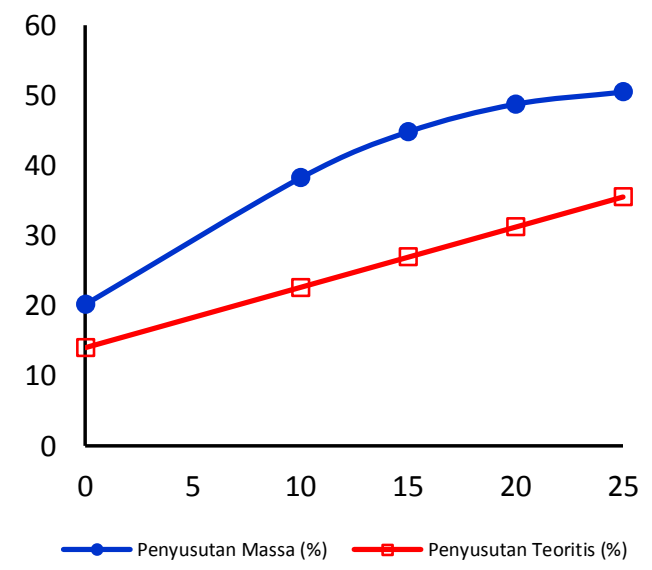

Figure 6. Effect of dry yeast powder weight fraction on mass reduction during the porous mullite ceramics sintering

Based on this phenomenon, the mass reduction during the sintering process could be estimated. For monolithic kaolin, mass reduction was be calculated theoretically based on the change from an initial condition as kaolin (Al2O3.SiO2.2H2O) into mullite and cristobalite. The amount of the theoretical mass reduction in the kaolin specimens which contained dry yeast powder was theoretically calculated based on kaolin mass reduction from the transformation into mullite and cristobalite and on the mass reduction from the firing of the dry yeast powder corresponding to the weight fractions. The theoretical and actual mass reductions can be seen in Figure 6. The difference between the actual and theoretical mass reductions was presumably caused by the presence of molasses which were added as binders during the green body formation and of the presence of moisture in the green body. The mass reductions of the specimens over the sintering process increased with the increase in dry yeast powder weight fraction.

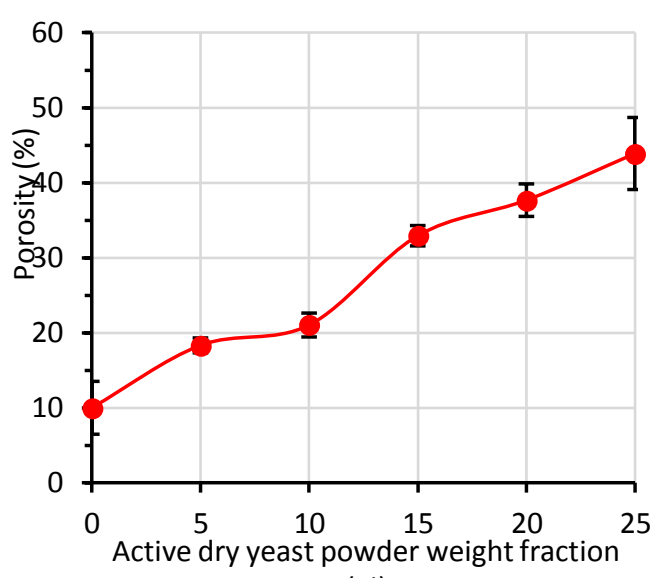

(\%)

Figure 7. Effect of dry yeast powder weight fraction on the porosity of the porous mullite ceramics

Over the sintering process course, the dry yeast powder was fired, leaving voids in the sintered specimens. With the increase in the dry yeast powder weight fractions the sintered specimens' porosity also increased. Porosity is a ratio of the voids' volume to the specimen's total volume. Porosity can be estimated based on the bulk density and theoretical density as follows (Wildan et al., 2009):

$$
\text { porosity }=1-\frac{\text { bulk density }}{\text { theoretical density }}
$$

The porosity of the sintered specimens increased with the increase in the dry yeast powder weight fraction as can be observed in Figure 7. Porosity rose from 9.98 $\pm 3.52 \%$ in specimen with $0 \%$ active dry yeast 
powder weight fraction into $43.87 \pm 4.80 \%$ in one with $25 \%$ active dry yeast powder weight fraction.

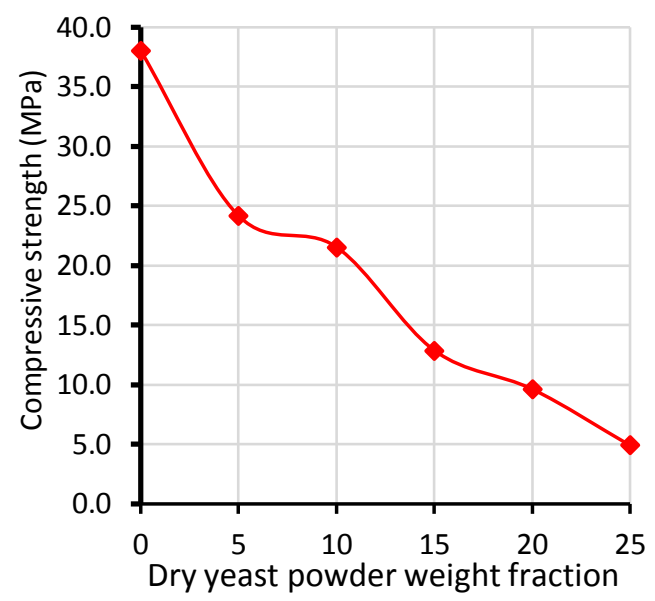

(\%)

Figure 8. Effect of dry yeast powder weight fraction on the compressive strength of the porous mullite ceramics

Figure 8 demonstrates the compressive strength of the sintered specimens as a function of dry yeast powder weight fraction. The compressive strength decreased with the increase in the dry yeast powder weight fraction. The compressive strength fell from $38.04 \square 5.02 \mathrm{MPa}$ in specimen with $0 \%$ dry yeast powder weight fraction into $4.92 \square 1.81 \mathrm{MPa}$ in one with $25 \%$ dry yeast powder weight fraction. This compressive strength drop was attributed to the rise of porosity, where porosity caused stress concentration and reduced the loadreceiving area (Barsoum, 2003).

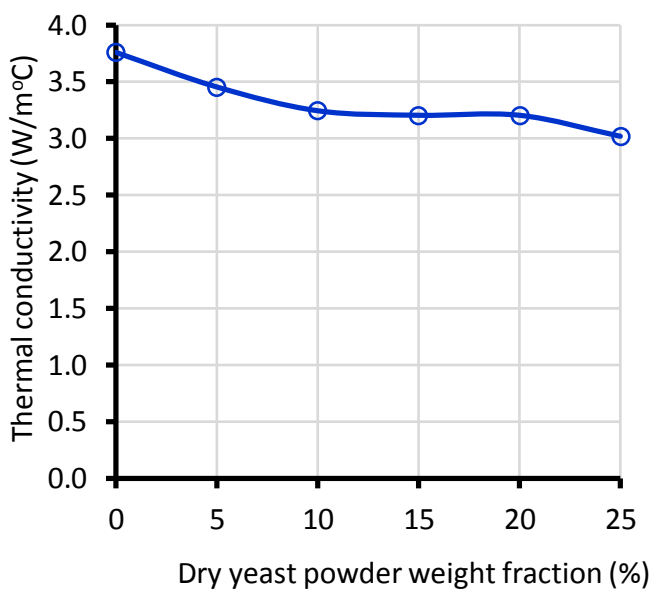

Figure 9. Effect of dry yeast powder weight fraction on the thermal conductivity of the porous mullite ceramics
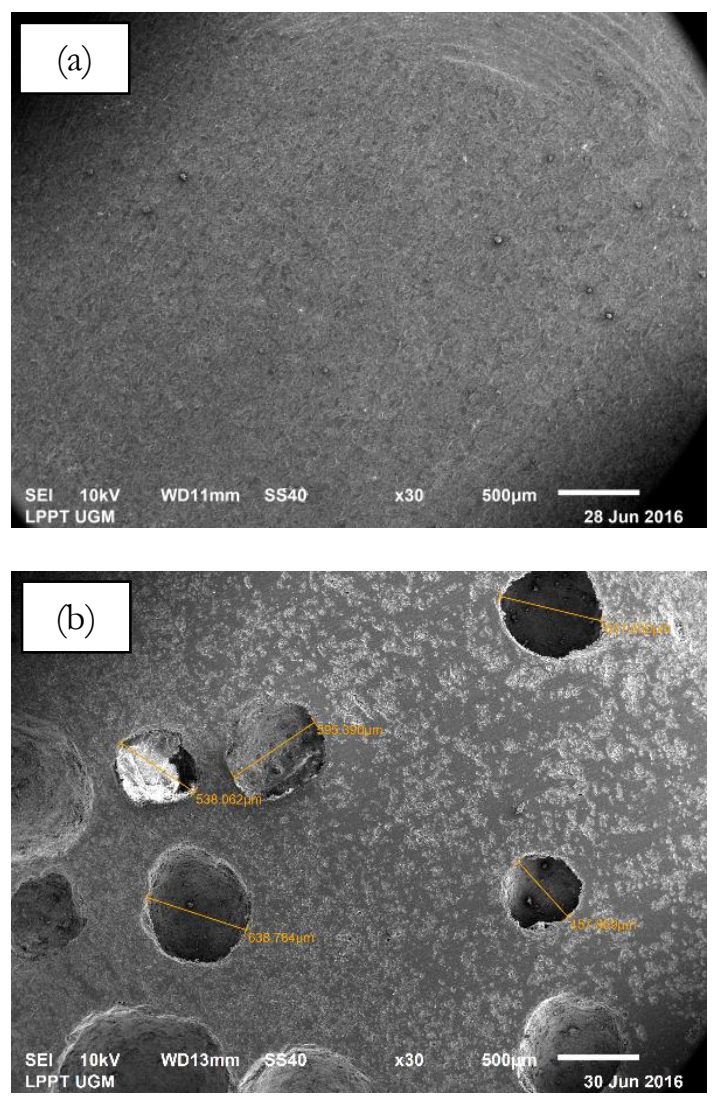

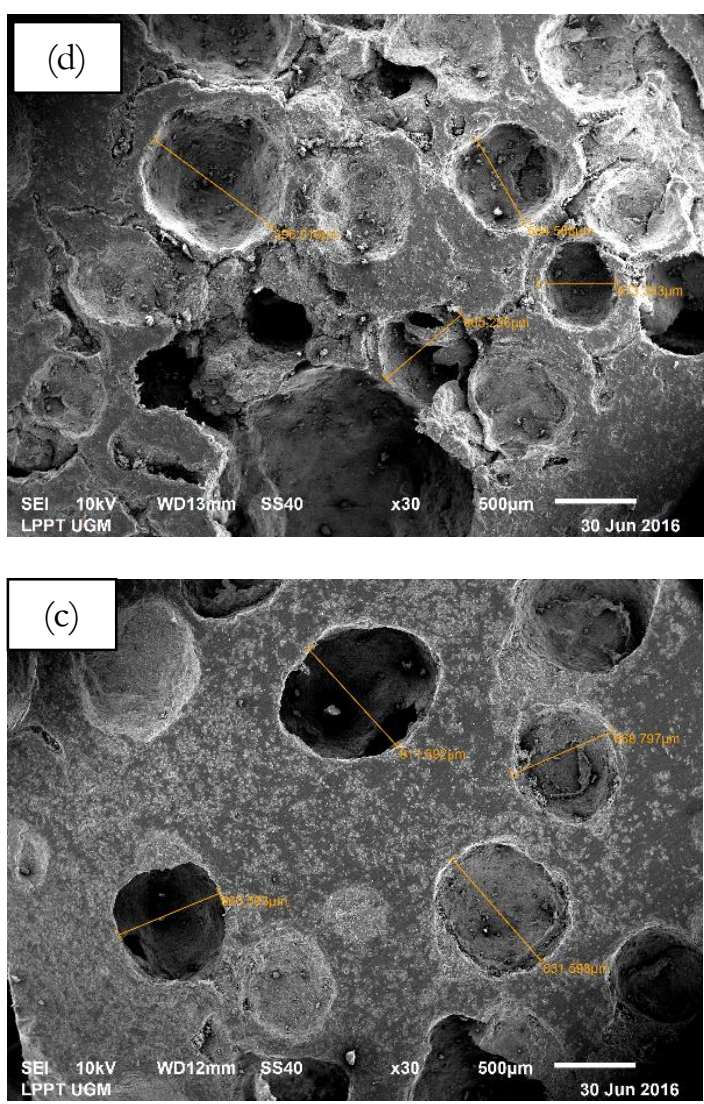

Figure 10. Specimens' microstructures as SEM-imaged for dry yeast powder weight fractions (a) $0 \%$, (b) $10 \%$, (c) 15\%, and (d) $25 \%$.

Figure 9 indicates the effect of the thermal conductivity of the sintered specimens on the dry yeast powder weight fraction. Thermal conductivity declined from $3.76 \mathrm{~W} / \mathrm{moC}$ in specimen with $0 \%$ dry yeast powder weight fraction to $3.01 \mathrm{~W} / \mathrm{moC}$ in one with $25 \%$ dry yeast powder weight fraction. This thermal conductivity fall was caused by the increase in porosity. Porosity plays a critical role in the thermal conductivity decrease in solids because air or void has very low conductivity in comparison to solid matters.

The microstructures of the sintered specimens can be observed in Figure 10. The pores were nearly spherical in shape. According to Figure 10, porosity increased with the increase in the dry yeast powder weight fraction.

\section{Conclusion}

The research results indicate that with the increase in the content of dry yeast powder as a PFA (pore-forming agent) in the mixture with kaolin, the bulk density decreased (from $2.44 \mathrm{gr} / \mathrm{cm} 3$ to $1.521 \mathrm{gr} / \mathrm{cm} 3)$, the porosity increased (from $23.77 \%$ to $52.48 \%$ ), the compressive strength decreased (from 38.04 $\mathrm{MPa}$ to $4.51 \mathrm{MPa}$ ), and the thermal conductivity decreased (from $3.76 \mathrm{~W} / \mathrm{moC}$ to $1.34 \mathrm{~W} / \mathrm{moC}$ ), each from $0 \%$ to $25 \%$ dry yeast powder contents. The raw material used was kaolin, which after being sintered at 1,450 oC transformed into mullite and cristobalite.

\section{Acknowledgements}

The authors would like to thank the Department of Mechanical and Industrial Engineering of the Faculty of Engineering, UGM, for providing research grant fund with contract no. 1576/H1.17/TMI/LK/2016.

\section{References}

[1] Barsoum, M, 2003, Fundamentals of Ceramics, McGraw Hill, Singapore

[2] Chen, C.Y. \& Tuan, W.H., 2001, "The Processing of Kaolin Powder Compact", Ceramics Internationals (27), 795-800.

[3] Chen, C.H., Takita, K., Ishiguro, S., Honda, S., Awaji, H., 2005, Fabrication of porous alumina tube by centrifugal molding, J. Eur. Ceram. Soc., 25(4), pp. 3257-3264.

[4] Cristobalite data, http://webmineral.com/data/Cristobalit e.shtml\#.W9Ot1pMzY2w

[5] Gregorova, E., Pabst, W, 2006, Porous ceramics prepared using poppy seed as pore-forming agent, Ceramics International.

[6] Gregorova, E., Pabst, and Bohacenko, I, 2006, Characterization of different starch types for their application in ceramic 
processing, J. Eur. Ceram. Soc., 26 (8), pp.1301-1309.

[7] Hammel E.C, Ighodaro, O.L.R, dan Okoli, O,I, 2014, Processing and properties of advanced porous ceramic: an application based review, Ceramics International, Vol 40(10), pp. 15351 15370

[8] Kingon, A. I., \& Davis, R.F., 2000, Engineering Properties of MultiComponent and Multiphase Oxides, in Ceramics and Glasses, Engineered Materials Handbook, Vol.4., ASM International, 758-774.

[9] Lee, W.E. \& Rainforth, W.M., 1994, Ceramic Microstructures Property Control by Prosessing, Chapman \& Hall, Sheffield University.

[10] Liu, P.S., dan Chen, G.F., Porous Materials, Processing and Applications, Tsinghwa University Press. 2014.

[11] Manap, N.R.A, dan Jais, U.S., 2009, Influence of concentration of pore forming agent on porosity of $\mathrm{SiO} 2$ ceramic from rice husk, Material Research Innovations, Vol 13(3), pp.382-385.

[12] Mullite data, http://webmineral.com/data/ mullite.shtml\#.W9Otc5MzY2w

[13] Sandra, K., Budi, A., dan Susilo, A. (2014). Pengaruh Suhu Sintering Terhadap Densitas dan Porositas pada Membran Keramik Berpori Berbasis Zeolit, Tanah Lempung, Arang Batok Kelapa dan PVA. Jurnal Fisika, Fakultas Matematika dan Ilmu Pengetahuan Alam, Universitas Negeri Jakarta.

[14] Wildan, MW, Suhanan dan Darwanto, 2009, Thermal conductivity and bending strength of porous mullite ceramics made by PFA method using corn starch, Jurnal Teknik Mesin ITS, Vol 9(3), hal. 149-155. 